\title{
A gênese do Inferno e do Purgatório na Divina Comédia de Dante: uma ponte possível entre Física e Literatura ${ }^{+*}$
}

Elso Drigo Filho ${ }^{1}$

Departamento de Física - Universidade Estadual Paulista

Campus de São José do Rio Preto

Maurizio Babini

Departamento de Letras Modernas - Universidade Estadual Paulista

Campus de São José do Rio Preto

São José do Rio Preto - SP

\section{Resumo}

Nas primeiras décadas de 1300, o escritor florentino Dante Alighieri compõe a Divina Comédia, uma viagem ao além, em que o autor descreve, baseando-se nas teorias cosmológicas, filosóficas e teológicas do seu tempo, o Inferno, o Purgatório e o Paraíso. A cratera do Inferno e a montanha do Purgatório teriam sido formadas pela queda de Lúcifer na Terra, após sua rebelião contra Deus. A ideia central desse texto é motivar a aprendizagem através de cálculos de grandezas físicas tendo como pano de fundo a cosmogonia da Idade Média. Nesse sentido, são estimadas, levando em conta as hipóteses formuladas, a velocidade de queda e a massa de Lúcifer. Espera-se que este trabalho possa contribuir para estreitar as relações entre Física e Literatura.

Palavras-chave: Didática da Física; Divina Comédia; Formação do Inferno; Formação do Purgatório; Massa de Lúcifer.

\footnotetext{
${ }^{+}$The genesis of Hell and Purgatory in Divine Comedy by Dante: a possible bridge between physics and literature

* Recebido: fevereiro de 2016.

Aceito: agosto de 2016.

1 E-mail: elso@ibilce.unesp.br

2 E-mail: maurizio@ibilce.unesp.br
} 


\begin{abstract}
In the first decades of the twelfth century, Dante Alighieri wrote the Divine Comedy. A text that describes a mythical journey in which the author describes the Inferno, Purgatory and Paradise based on cosmology, philosophy and theology of his time. The crater of the Hell and the mountain of the Purgatory have been formed by the fal of Lucifer on the Earth, after his rebellion against God. The central idea of this paper is to motive students from the calculation of physical quantities using, as background, the cosmogony of the Middle Ages. In this context, it is estimated the speed and the mass of Lucifer. It is hoped that this work can help to bridge the gap between Physics and Literature.
\end{abstract}

Keywords: Didactics in Physics Context; Divine Comedy; Hell; Purgatory; Mass of Lucifer.

\title{
I. Introdução
}

Temas relacionados à ciência por vezes geram discussões e impactos em diversas áreas do conhecimento humano, alguns com caráter mais tecnológico, outros com teor mais humanista. Um desses temas humanistas tem raízes nos argumentos de Sir Charles P. Snow (SNOW, 1956) sobre a divisão entre a cultura literária (representante da cultura humanista) e da cultura das ciências naturais (representada, essencialmente, pela física). As ideias expressas por Snow geraram grandes controvérsias das quais participaram personalidades influentes das duas culturas da época como ressaltado por Mecke (2004), no capítulo As duas culturas uma história escandalosa?, onde se lê que "No debate alargado participaram não só físicos, como Robert Oppenheimer, mas também críticos literários e escritores, como Aldous Huxley" (MECKE, 2004, p. 5).

De forma interativa, as discussões suscitadas pela relação entre física e as artes tiveram reflexos no Ensino de Física, gerando grande diversidade de sugestões e uma riqueza de propostas e ações voltadas a tornar o aprendizado dessa ciência mais atrativo e motivador, além de permitir ao educando desenvolver um conhecimento mais profundo, tanto formal como conceitual. Em particular no Brasil, propostas de tratar conceitos físicos no contexto das artes têm sido apresentadas e exemplos podem ser citados referentes à literatura (ZANETIC, 2005; 2006; FERREIRA, 2003), à pintura (ANDRADE, 2007), ás artes cênicas (JÚDICE, 2001), entre outros. Em relação à física e literatura uma revisão abrangente foi publicada por Lima e Ricardo (2015).

Os trabalhos que têm se voltado para a relação específica entre Física e Literatura indicam que o tema pode ser abordado através de diferentes perspectivas. Para fins didáticos, o uso de literatura específica de divulgação científica ou textos literários em que um ou mais 
conceitos físicos são evidenciados no decorrer da trama são exemplos onde essa relação pode ser profícua. Lima e Ricardo (2015) explicita uma classificação dos trabalhos nessa linha em três categorias. Seguindo essa categorização o presente artigo se aproxima mais da terceira categoria que enfatiza o uso de analogias e metáforas no ensino de física.

Neste trabalho, tendo como pano de fundo a concepção de mundo proposta por Dante Alighieri em seu livro A Divina Comédia (ALIGHIERI, 1595), usamos as leis físicas da Mecânica para estimar qual seria a velocidade de queda e a massa do "anjo caído". Esse evento, a queda de Lúcifer, segundo a visão vigente na Idade Média Europeia, teria causado a formação da cratera do Inferno e a montanha do Purgatório. Acreditamos que a contextualização do problema tratado pode contribuir para no processo de ensino/aprendizagem em diferentes aspectos. Essa contribuição permeia diversos níveis do processo em questão, tais como a motivação dos educados, comparação de visões de mundo, acompanhamento da construção de modelos a partir de hipóteses, construção de uma perspectiva histórica do conhecimento humano, entre outros. Além disso, é possível introduzir a obra de Dante (uma das mais fascinantes da literatura universal/ocidental) e motivar sua leitura, promovendo uma ponte educacional entre a Física e a Literatura como indicado em outros trabalhos (GUILGER, 2015; NEVES, 1998).

Considerando os conceitos físicos e matemáticos que servem de base ao presente estudo, esse trabalho se destina inicialmente a alunos do curso superior. Entretanto, o conteúdo pode ser adaptado para outros níveis de ensino. No apêndice, apresentamos uma versão do tema abordado direcionada ao Ensino Médio.

Antes de prosseguir é importante lembrar que, embora a ficção literária seja usada como contexto para abordagem dos conceitos, o uso das leis físicas nesse trabalho é o mais preciso possível. Algumas aproximações são introduzidas, no entanto elas são apontadas e discutidas para que fique claro quais hipóteses estão sendo usadas e quais simplificações estão sendo introduzidas.

Por fim, desejamos ao leitor uma boa leitura. Embora ela possa ser árdua em alguns pontos, esperamos não precisar adverti-lo com as palavras: "Deixai aqui ó vós que entrais todas as esperanças" (in: Alighieri, 1595, canto III, verso 9) como Dante leu às portas do Inferno.

\section{Universo literário abordado}

A Divina Comédia do escritor florentino Dante Alighieri há séculos fascina leitores de todas as gerações por sua complexidade e grandiosidade. Dante imagina ter visitado o mundo do além-morte, começando sua viagem na noite de Natal de 1300. De acordo com as teorias vigentes à época ligadas, sobretudo, à Igreja Católica, o além se dividia em três reinos: Inferno, Purgatório e Paraíso. Dentre os três reinos, o Inferno teria um caráter permanente (a condenação ao inferno seria eterna) e o tratamento reservado aos pecadores seria duríssimo. Os demais reinos seriam provisórios: depois do julgamento final, haveria, de acordo com a 
teologia católica, a ressurreição dos corpos. Uma questão coerente nesse contexto, formulada como consequência direta dessa visão de mundo, era: como se formaram os três reinos?

A resposta a essa questão é dividida em duas partes. A primeira diz respeito ao Paraíso, que teria sido construído por Deus quando da criação do universo. Os outros dois reinos teriam sido criados como resultado da queda de Lúcifer na Terra, que ocorreu depois dele liderar uma rebelião dos anjos. O impacto teria ocorrido onde hoje se encontra a cidade de Jerusalém e resultaria na imensa cratera do Inferno, cuja profundeza chegaria ao centro da Terra. E, lá no centro da Terra, o próprio Lúcifer se encontra aprisionado, enterrado até a cintura em um lago gelado. De acordo com a concepção da época, as terras teriam se retraído diante da chegada do mal, ou seja, pelo horror causado pela chegada de Lúcifer.

O Inferno seria composto de nove círculos concêntricos que vão se afunilando. Nos primeiros círculos são punidos os pecados menos graves, começando pela luxúria. Depois de ter descido até o lugar onde estaria Lúcifer, Dante teria subido por uma estreita passagem, que o escritor chama de "natural burella", e subido até uma ilha, localizada no hemisfério austral, em que surge a montanha do Purgatório. De acordo com o pensamento da época, nesse hemisfério haveria somente águas. A montanha do Purgatório formou-se, de acordo com Dante, sucessivamente à formação da cratera do Inferno, utilizando o próprio material saído do buraco. No cimo da montanha do Purgatório se encontra o Paraíso terrestre onde, posteriormente, foram colocados Adão e Eva. Simbolicamente o Paraíso terrestre é o lugar da Terra mais perto do Paraíso sendo, por essa razão, o mais perfeito. Na Fig. 1, é possível observar a representação dos primeiros dois reinos do além de acordo com o quadro proposto por Dante em sua obra.
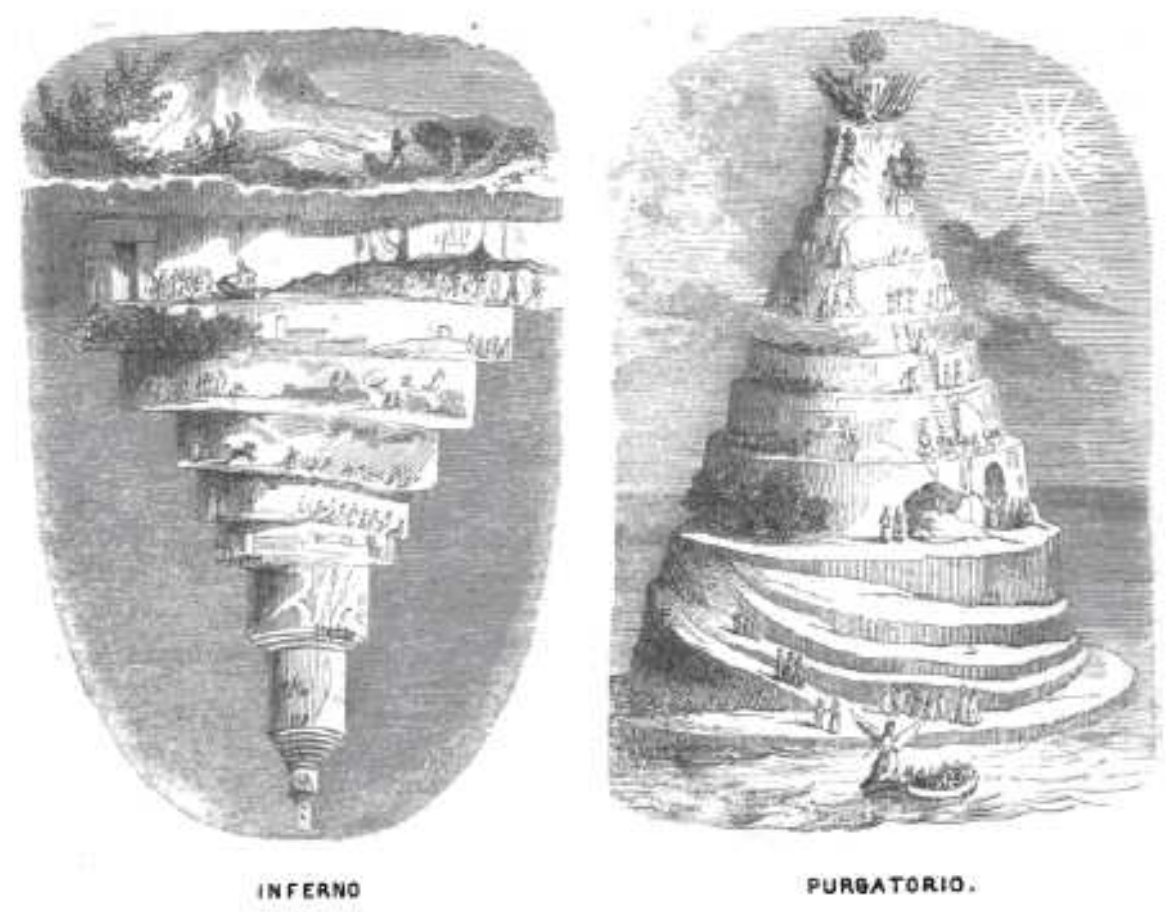

Fig. 1 -Representação do Inferno e do Purgatório (Fonte: ALIGHIERI, 1844, p. xvi). 
Acima da Terra, que permanece imóvel e é o centro do universo de acordo com o sistema ptolemaico, está o Paraíso, que é formado por nove céus, esferas concêntricas, sete das quais correspondem aos planetas do sistema ptolemaico, isto é Lua, Mercúrio, Vênus, Sol, Marte, Júpiter e Saturno. O oitavo céu seria formado pelas estrelas fixas, e nono, o primeiro móvel (Primo Mobile), é o céu dos Serafins. Além desses céus fica o Empíreo que é imóvel e o local onde estaria Deus.

O mundo dantesco é, portanto, um mundo complexo, feito não somente de imagens alegóricas e de criações literárias. Ele é uma súmula do saber filosófico, cosmológico e teológico aquinhoado até então. Dante era certamente um intelectual e erudito, seu conhecimento foi adquirido por meio do estudo das principais obras do seu tempo.

\section{A velocidade de queda}

O começo de nossa análise física sobre a obra de Dante nos leva a refletir sobre a queda em si. Lúcifer comete o pecado da soberba e como punição é afastado do Céu, caindo na Terra. Uma vez que ele cai, não sendo empurrado ou arremessado, sua velocidade inicial pode ser considerada igual a zero e é preciso saber de onde a queda se inicia. A questão inicial que se coloca aqui é: onde fica o limite do primeiro céu?

Tendo em vista o fato de que o primeiro céu corresponde à Lua, a resposta mais convincente parece ser: o primeiro céu inicia à distância onde a gravidade da Terra é igual à da Lua. Dessa forma, um corpo mais próximo da Lua que essa distância, estaria sob a influência da Lua, portanto no primeiro céu. Um corpo parado nesse ponto começará a cair em direção a Terra apenas com um pequeno deslocamento em sua direção. Assim, vamos começar identificando esse ponto.

Consideremos um corpo, de massa m, na posição exata onde a força gravitacional da Terra $\left(\vec{F}_{T}\right)$ é igual à da Lua $\left(\vec{F}_{L}\right)$. Nesse caso, admitindo que as forças atuem em sentidos opostos, seus módulos devem ser iguais, $F_{T}=F_{L}$, ou seja:

$$
\frac{G M_{T} m}{d_{T}^{2}}=\frac{G M_{L} m}{d_{L}^{2}} \rightarrow \frac{d_{T}}{d_{L}}=\left(\frac{M_{T}}{M_{L}}\right)^{1 / 2} \approx 9 .
$$

Nessa relação, foi usada a expressão da força gravitacional introduzida por Newton (RESNICK, 1974), $\mathrm{M}_{\mathrm{T}}$ representa a massa da Terra (cerca de $6.10^{24} \mathrm{~kg}$ ), $\mathrm{M}_{\mathrm{L}}$ é a massa da Lua $\left(7,4.10^{22} \mathrm{~kg}\right), \mathrm{G}$ é a constante da gravitação universal $\left(6,67.10^{-11} \mathrm{~N} . \mathrm{m}^{2} / \mathrm{kg}\right), \mathrm{d}_{\mathrm{T}}$ é a distância entre a Terra e o ponto procurado e $d_{L}$ é a distância entre este ponto e a Lua. Usando a relação acima (1), o conhecimento de que a distância entre a Terra e a Lua (DT-L) vale 3,8.10 $m$ e que $\mathrm{D}_{\mathrm{T}-\mathrm{L}}=\mathrm{d}_{\mathrm{T}}+\mathrm{d}_{\mathrm{L}}$, obtemos que $\mathrm{d}_{\mathrm{T}}=3,4 \cdot 10^{8} \mathrm{~m}=3,4 \cdot 10^{5} \mathrm{~km}$. Essa distância representaria o tamanho da queda do anjo, ou seja, trezentos e quarenta mil quilômetros. Para essa distância não é possível admitir que a aceleração da gravidade seja constante. Entretanto, para fins didáticos, uma aproximação inicial pode ser feita considerando a aceleração da gravidade cons- 
tante $(\mathrm{g})$, digamos $9,8 \mathrm{~m} / \mathrm{s}^{2}$. Com essa aproximação o conteúdo tratado aqui pode ser discutido também no Ensino Médio (vide o apêndice do presente artigo).

Um cálculo mais rigoroso para se determinar a velocidade com que o Lúcifer atingiria a superfície da Terra pode ser feito usando a conservação de energia. Para tanto, um pouco de cálculo integral é necessário. A variação da energia potencial $(\Delta U)$ é encontrada pela integral da força, nesse caso, a força gravitacional. Assim, temos:

$$
\Delta U=-\int_{d_{T}}^{R_{T}} \frac{G M_{T} M_{L u}}{r^{2}} d r=-G M_{T} M_{L u}\left[\frac{1}{d_{T}}-\frac{1}{R_{T}}\right] \cong 6,1 \cdot 10^{7} M_{L u},
$$

sendo que $\mathrm{M}_{L u}$ corresponde a massa de Lúcifer, $\mathrm{R}_{\mathrm{T}}$ é o raio da Terra $\left(6,4.10^{6} \mathrm{~m}\right)$ e o restante dos símbolos são os mesmos usados anteriormente. Desprezando o atrito, a conservação da energia mecânica impõe que a energia cinética final $\left(E_{c}=m \cdot v^{2} / 2\right)$ de Lúcifer deve ser igual à variação da energia potencial, lembrando que estamos admitindo que ele parte do repouso. Dessa forma, igualando o resultado indicado em (2) à energia cinética, se obtém:

$$
E_{c}=\frac{M_{L u} v^{2}}{2}=6,1 \cdot 10^{7} M_{L u} \rightarrow v=1,1 \cdot 10^{4} \mathrm{~m} / \mathrm{s}
$$

Como esperado essa velocidade é muito alta no sentido cotidiano, cerca de $11 \mathrm{~km} / \mathrm{s}$, mas é relativamente pequena se comparada a velocidade da luz $\left(3.10^{8} \mathrm{~m} / \mathrm{s}\right)$. Desta forma, o problema pode ser tratado classicamente, sem necessidade de fazer correções relativísticas.

Um ponto a ser destacado é que nos cálculos feitos acima se desprezou a resistência do ar. Esse efeito deve ser importante considerando o valor da velocidade obtida. Entretanto, uma vez que a distância entre a Terra e o início da queda vale $\mathrm{d}_{\mathrm{T}}=3,4 \cdot 10^{8} \mathrm{~m}=3,4 \cdot 10^{5} \mathrm{~km}$ e a espessura da atmosfera é da ordem de $100 \mathrm{~km}=10^{2} \mathrm{~km}$, o trecho no qual haveria ação da resistência do ar corresponde a menos de um milésimo da trajetória total. Essa relação fornece uma justificativa para se admitir que os efeitos de resistência do ar sejam pequenos frente ao movimento total e, portanto, podem ser desprezados em uma primeira aproximação.

\section{A Cratera do Inferno e a Montanha do Purgatório}

Seguindo adiante na análise, vamos estimar qual seriam as dimensões da Montanha do Purgatório, criada pelo impacto de Lúcifer na Terra, para tanto, de acordo com Dante, consideremos que Lúcifer está no ponto mais profundo do Inferno, que deveria coincidir com o centro da Terra. Assim, o modelo que emerge é que ele ao atingir a superfície do planeta teria criado o Inferno e elevado, do outro lado da Terra, a Montanha do Purgatório. Seguindo essa ideia, vamos aproximar a montanha como sendo um cone cuja área da base é $\mathrm{A}_{\mathrm{b}} \mathrm{e}$ a altura coincide com o raio da Terra $\left(\mathrm{R}_{\mathrm{T}}\right)$. Essa descrição parece ser amparada pela cosmologia explicitada por Dante, os círculos do Inferno se afunilam até chegar ao último e a Montanha do Purgatório teria base larga e se estreitaria até chegar ao paraíso terrestre (Figura 1). 
O volume do cone (V) é relativamente fácil de calcular e pode ser obtido multiplicando a área da base pela altura do cone e dividindo por três, no presente caso: $V=A_{b} \cdot R_{T} / 3$. Este valor pode ser determinado considerando discos sobrepostos de espessura infinitesimal, a soma (integração) da massa de todos os discos fornece o volume total do cone. Uma descrição geral do cálculo do volume de um corpo em função das áreas de secções paralelas pode ser encontrada em livros de cálculo (vide, por exemplo, PISKUNOV, 1983).

Muitos estudiosos da obra de Dante atentaram para dados quantitativos relacionados com a Divina Comédia, em particular, no que diz respeito sua topografia. Esses dados são importantes para os cálculos desenvolvidos mais adiante.

O primeiro estudo de grande importância a esse respeito foi desenvolvido pelo humanista, arquiteto e matemático florentino Antonio di Tuccio Manetti (1423-1497). Este trabalho (MANETTI, 1506) é escrito na forma de um diálogo entre o próprio Manetti e o poeta florentino Girolamo Benivieni (1453-1542). Benivieni é o responsável pela publicação póstuma dessa obra de Manetti em Florença pela imprensa do governo da cidade ("Giunta"). O Diálogo foi sucessivamente republicado em várias edições e coletâneas, dentre elas a obra muito divulgada publicada por Gigli (1855).

Antonio Manetti baseando-se na obra original de Dante fornece vários dados sobre as dimensões da cratera do Inferno. A Figura 2, que reproduz um mapa do Inferno de Dante, redesenhado a partir das medidas propostas por Manetti, foi publicada pela primeira vez na edição da Divina Comédia de 1595 organizada pela Accademia della Crusca de Florença, impressa pelo editor Domenico Manzani (ALIGHIERI, 1595).

De acordo com Manetti, o buraco do Inferno teria um diâmetro enorme. O tamanho da boca do Inferno é obtido partindo de um arco de 3.400 milhas que é igual a um sexto da medida da circunferência da Terra, tendo como centro Jerusalém. Assim, o topo da cratera se estenderia 1700 milhas a direita e 1700 milhas a esquerda da cidade sagrada. A corda formada por esse arco é igual ao raio da Terra, que de acordo com os dados da época seria de 3245 5/11 milhas ( 3245,45 milhas). Este valor, que não difere muito do valor atual, já era conhecido na época de Dante e estava contido, por exemplo, no livro Tresor de Brunetto Latini (1220-1294) (LATINI, 2007) que foi a primeira enciclopédia popular do mundo ocidental. O Tresor, cujo título original era Li livres dou tresor, obra em três volumes, foi escrito durante o exílio de Brunetto Latini na França entre 1260 e 1266.

Para determinar a dimensão da boca da cratera temos que conhecer a largura do primeiro círculo do Inferno. Inicialmente, é importante notar que antes da entrada do Inferno se localizaria o Limbo, local destinado às almas dos que não pecaram, mas que nasceram antes de Jesus Cristo e não tiveram, portanto, a oportunidade de conhecer a religião cristã. É nesse local que Dante encontra o poeta Virgílio que lhe serve de guia na travessia do Inferno e do Purgatório. De acordo com Manetti, o Limbo teria 87,5 milhas de extensão contornando toda a entrada da cratera. Assim, para determinar o diâmetro do primeiro círculo do Inferno $\left(D_{i}\right)$ 
seria necessário subtrair a distância correspondente ao Limbo, o que resultaria em um diâmetro de $\mathrm{D}_{\mathrm{i}}=3245,45-2 \times 87,5=3070,45$ milhas.

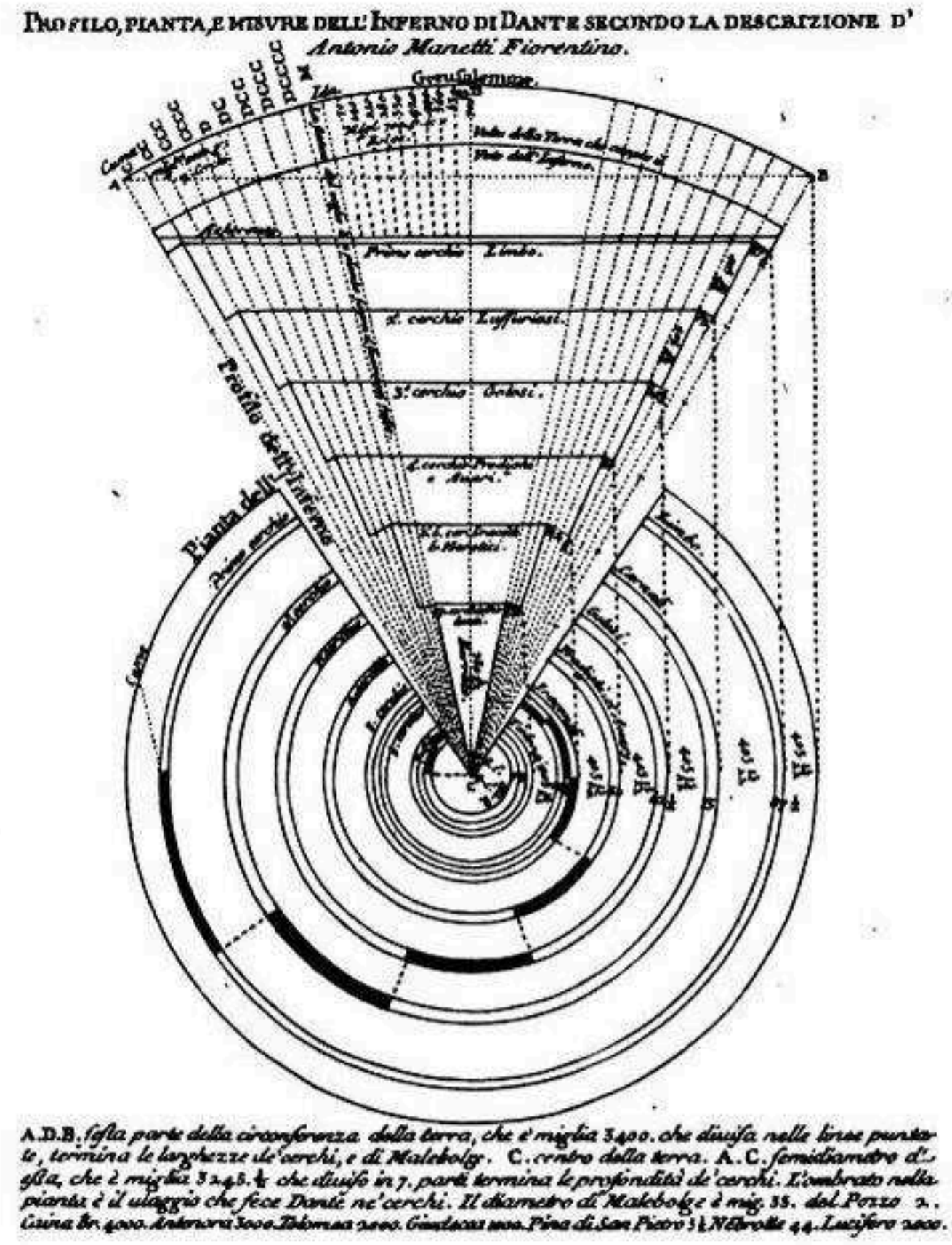

Fig. 2 - Mapa do Inferno. Desenho feito a partir dos estudos de Antonio Manetti (ALIGHIERI, 1595).

Em 1544 foi impressa em Veneza outra edição da Divina Commedia de Dante Alighieri (ALIGHIERI, 1544) comentada por Alessandro Vellutello, um literato de Lucca, cidade da Toscana, que viveu em Veneza no período da Renascença. Nessa edição está contido o capítulo Descrittione de lo inferno ("Descrição do inferno"), em que o autor, apresenta 
novas reflexões acerca da cosmologia dantesca e sobre a topografia dos três reinos, criticando o trabalho do predecessor e propondo, inclusive, medidas bem diferentes das propostas por Manetti. Sem analisar em detalhes as diferenças entre as duas propostas, cabe destacar que o diâmetro da boca do Inferno de Vellutello é de 280 milhas, um valor bem menor que o atribuído por Manetti.

A publicação do trabalho de Vellutello gerou muita polêmica, sobretudo em ambientes florentinos. Mais tarde, Galileu Galilei foi convidado pela Accademia Fiorentina para debater e comparar as duas hipóteses. O resultado da análise de Galileu foi apresentado em duas lições feitas em 1588. As lições de Galileu Galilei estão contidas em muitas obras e coletâneas posteriores de escritos do cientista, dentre elas a de Gigli (GIGLI, 1855). No que diz respeito ao tamanho do Inferno, Galilei indica ser mais "verosememelhante" o trabalho de Manetti (GIGLI, 1855). Difícil saber quanto o fato de Manetti ser florentino e Vellutello de Lucca (cidade rival de Florença) tenha pesado na decisão de Galilei, que embora pisano, devia ter propensão para comprazer a elite florentina da época.

No que diz respeito ao vão do Inferno, Galileu, que não calcula com precisão o seu tamanho, afirma que não deve ser considerado igual a um sexto do volume da Terra, mas que provavelmente deveria ser igual à cerca de um quatorze avos desse. Os argumentos de Galileu levam em conta a estabilidade da estrutura que cobriria a cratera do Inferno. Nessas condições o diâmetro da cratera seria igual ao raio da Terra.

Outros autores apresentaram outros cálculos e modelos sobre a topografia do Inferno, mostrando interesse e criatividade sobre o assunto. No presente trabalho, utilizaremos a medida proposta por Manetti, tendo em vista o fato de que o próprio Galileu Galilei a considerou como sendo mais confiável que a medida proposta por Vellutello. Nada impede, contudo, que o leitor interessado refaça os cálculos levando em conta outra hipótese acerca do tamanho da cratera.

Para continuar nosso trabalho faz-se necessário converter as medidas em milhas propostas por Manetti para quilômetros. A medida do "miglio" fiorentino é, de acordo os estudiosos de metrologia, de 1653,607 metros (BARATTA, 1903, p. 37). Entretanto, esse fator de conversão aplicado ao valor indicado por Manetti (3070,45 milhas) fornece um diâmetro da cratera de $(3070,45) \times(1653,607) \approx 5077317,61 \mathrm{~m} \approx 5,0810^{6} \mathrm{~m}$ que é cerca de $20 \%$ inferior ao raio médio da Terra conhecido hoje em dia $\left(6,37.10^{6} \mathrm{~m}\right)$. Pode-se corrigir essa diferença igualando a proporção entre o raio da Terra conhecido hoje $(6372,97 \mathrm{~km})$ e o raio indicado por Manetti (3245,45 milhas). Nessas condições, o diâmetro da cratera seria $6029 \mathrm{~km}$ o que corresponde a um raio de cerca de $\mathrm{R}_{\mathrm{b}}=3,010^{6} \mathrm{~m}$, metade do diâmetro. Assim, vamos adotar esse valor como sendo a dimensão da boca da cratera aberta pela queda de Lúcifer.

Nas condições descritas acima, o volume da Montanha do Purgatório seria igual ao volume de um cone:

$$
V=\frac{A_{b} R_{T}}{3}=\frac{\pi R_{b}^{2} R_{T}}{3}=\frac{\pi\left(3 \cdot 10^{6}\right)^{2} 6,4 \cdot 10^{6}}{3}=6,0.10^{19} \mathrm{~m}^{3} .
$$


Admitindo que a base fosse circular, ou seja, a área vale $A_{b}=\pi \cdot R_{b}{ }^{2}$, o que faria jus aos chamados "círculos" tanto do Inferno como do Purgatório.

Outra grandeza importante a ser calculada é a massa da montanha (m), para tanto precisamos da densidade da Terra $\left(\rho_{\mathrm{T}}\right)$. Essa densidade pode ser obtida dividindo a massa do planeta pelo seu volume $\left(\mathrm{V}_{\mathrm{T}}=4 \pi \times \mathrm{R}_{\mathrm{T}}^{3} / 3\right.$, admitindo uma forma esférica), ou seja:

$$
\rho_{T}=\frac{M_{T}}{V_{T}}=5,5 \cdot 10^{3} \mathrm{~kg} / \mathrm{m}^{3} .
$$

Esse valor é o mesmo indicado na literatura sobre o assunto. Por exemplo, um livro de física básica (RESNICK, 1974) fornece o valor de $5,52.10^{3} \mathrm{~kg} / \mathrm{m}^{3}$ para tal densidade.

Usando a definição de densidade mais uma vez e os valores indicados em (4) e (5), a massa da montanha pode ser determinada:

$$
m=\rho_{T} V=5,5.10^{3} \times 6,0.10^{19}=3,3.10^{23} \mathrm{k} .
$$

\section{A Massa de Lúcifer}

O cálculo realizado para determinar a massa de Lúcifer é bastante aproximado, pois vamos admitir conservação da energia mecânica o que não parece ser o caso, uma vez que as forças dissipativas devem ser importantes no processo. Assim, a estimativa a seguir deve ser entendida como um limite inferior da massa do anjo.

Inicialmente, vamos calcular a energia potencial da Montanha do Purgatório. É importante atentar para o fato da aceleração da gravidade variar para diferentes alturas da montanha, um cálculo rápido mostra que essa aceleração no topo (a uma altura igual ao raio da Terra) valeria cerca de $2,4 \mathrm{~m} / \mathrm{s}^{2}$, em contraste com o valor na sua base, que teria um valor próximo a $9,8 \mathrm{~m} / \mathrm{s}^{2}$. Assim, o cálculo a ser feito envolve determinar a energia potencial de discos sobrepostos cujos raios diminuem da base para o topo, formando um cone, e somar todas essas energia. Ao longo do processo, vamos assumir que as espessuras dos discos são bastante pequenas, ou seja, teremos que fazer uma integração.

De forma geral, a energia potencial de um disco de massa infinitesimal ( $\mathrm{d} m$ ) a uma altura $\left(R_{T}+y\right)$ é dado por:

$$
d U=\frac{G M_{T}}{R_{T}+y} d m
$$

Lembrando que a montanha estaria acima da superfície, ou seja, sua altura (y) é contada a partir do raio da Terra $\left(\mathrm{R}_{\mathrm{T}}\right)$. O elemento de massa $\mathrm{d} m$ pode ser determinado pelo produto da densidade $\left(\rho_{T}\right)$, já calculado anteriormente, pelo volume do disco $\left(\mathrm{V}_{\mathrm{d}}\right)$. O volume do disco, por sua vez, é calculado multiplicando a área da base pela sua altura (dy). Finalmente, é oportuno lembrar que a área da base de cada disco é igual à área de um círculo cujo raio depende a altura, $\mathrm{r}(y)$. 
A relação entre os raios dos discos e suas respectivas alturas pode ser obtida tomando um corte longitudinal do cone, que o divide em duas partes iguais, e usando um pouco de trigonometria, especificamente, semelhança de triângulos. A figura 3 mostra um esquema da geometria indicada acima. Assim, é possível estabelecer:

$$
r(y)=\frac{\left(R_{T}-y\right) R_{b}}{R_{T}}
$$

sendo $\mathrm{R}_{\mathrm{b}} \mathrm{o}$ raio da base. Nesse cálculo é admitindo que o raio da Terra seja igual à altura do cone, o que combina com a visão dantesca da Montanha do Purgatório.

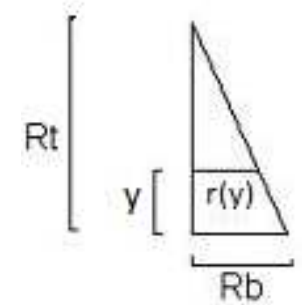

Fig. 3 - Visualização dos triângulos para determinar a relação (8).

Usando a densidade da Terra (5) e o volume de cada disco $\mathrm{V}_{\mathrm{d}}$ (o volume de um cilindro de espessura dy), o elemento de massa é dado por:

$$
d m=\rho_{T} V_{d}=\rho_{T} \pi\left(\frac{\left(R_{T}-y\right) R_{b}}{R_{T}}\right)^{2} d y
$$

sendo o volume do disco é igual a área da base vezes a sua altura, ou seja, $\mathrm{V}_{\mathrm{d}}=\pi[\mathrm{r}(y)]^{2} . \mathrm{d} y$, com r(y) dado pela relação (8).

Nas condições indicadas acima, a energia potencial, relação (7), pode ser reescrita usando (9):

$$
d U=\frac{G M_{T}}{R_{T}+y} \rho_{T} \pi\left(\frac{\left(R_{T}-y\right) R_{b}}{R_{T}}\right)^{2} d y
$$

Por fim, a integração nos extremos de $\mathrm{R}_{\mathrm{T}}$ (base da montanha) até 2. $\mathrm{R}_{\mathrm{T}}$ (topo da montanha) fornece a energia potencial da montanha, ou seja,

$$
\Delta U=\int_{R_{T}}^{2 R_{T}}\left\{\frac{G M_{T}}{R_{T}+y} \rho_{T} \pi\left(\frac{\left(R_{T}-y\right) R_{b}}{R_{T}}\right)^{2}\right\} d y=G M_{T} \rho_{T} \pi\left(\frac{R_{b}}{R_{T}}\right)^{2} \int_{R_{T}}^{2 R_{T}} \frac{\left(R_{T}-y\right)^{2}}{R_{T}+y} d y .
$$

A integral acima pode ser calculada substituindo $y=\mathrm{u}-\mathrm{R}_{\mathrm{T}}$ e tomando cuidado com os extremos de integração. O cálculo em si é deixado para o leitor, o resultado final vale:

$$
\Delta U=0,12 \pi G M_{T} \rho_{T} R_{b}^{2} \approx 7,5 \cdot 10^{30} \mathrm{~J}
$$


Uma vez determinada a energia potencial da montanha, o próximo passo é determinar a velocidade inicial do conjunto (Lúcifer + montanha). Como Lúcifer devia ter ficado encravado no fundo do Inferno, o natural é supor que houve um choque completamente inelástico. Assim, por conservação do momento linear tem-se que:

$$
M_{L u} v=\left(M_{L u}+m\right) v_{c o n j} \rightarrow v_{c o n j}=\frac{M_{L u} v}{\left(M_{L u}+m\right)}
$$

sendo que $M_{L u}$ representa a massa de Lúcifer, $v$ a sua velocidade ao atingir a superfície da Terra (3), $m$ a massa da montanha (6) e $v_{\text {conj }}$ é a velocidade do conjunto logo após o choque.

Para achar uma estimativa da massa de Lúcifer devemos observar que, no mínimo, durante o processo de colisão, a energia cinética do conjunto $\left(E_{c}\right)$ foi transformada em energia potencial da montanha (12). Essa estimativa, embora grosseira, pois despreza efeitos importantes, como as forças dispersivas, fornece ao menos um limite inferior para a massa procurada. Entretanto, considerando a visão da Idade Média, pode-se argumentar que seria aceitável admitir a hipótese de que a dissipação de energia fosse minimizada nesse processo uma vez que se imagina que a própria matéria se retrairia com a aproximação do mal (in: ALIGHIERI, 1595, Inferno, Canto XXXIV, v. 121-126).

Seguindo o raciocínio indicado acima, igualando a energia cinética inicial com a energia potencial da montanha e usando a velocidade do conjunto obtida na relação (13), temos:

$$
\Delta U=\frac{\left(M_{L u}+m\right)\left(v_{c o n j}\right)^{2}}{2}=\frac{M_{L u}^{2} v^{2}}{2\left(M_{L u}+m\right)}
$$

ou seja:

$$
M_{L u}^{2} v^{2}-2 \Delta U M_{L u}-2 m \Delta U=0
$$

Essa última expressão é uma equação de segundo grau em MLu, cuja solução pode ser determinada pela relação:

$$
M_{L u}=\frac{\Delta U \pm \sqrt{\Delta U\left(\Delta U+2 m v^{2}\right)}}{v^{2}} .
$$

Como a massa deve ser positiva a solução possível para a equação (16) envolve o sinal positivo (+) antes da raiz quadrada. Isso é facilmente percebido observando que o termo dentro da raiz é sempre maior que $\Delta U$.

Usando os valores já encontrados de $\Delta \mathrm{U}=7,5.10^{30} \mathrm{~J}$ (expressão (12)), $\mathrm{v}=1,1.10^{4}$ $\mathrm{m} / \mathrm{s}$ (expressão (3)), $\mathrm{m}=3,3.10^{23} \mathrm{~kg}$ (expressão (6)) e a equação (16), obtêm-se um valor final para a massa de Lúcifer. É conveniente observar que o produto $2 \mathrm{mv}^{2}\left(\sim 80.10^{30}\right)$ dentro da raiz da expressão (14) tem uma ordem de grandeza próxima a de $\Delta U$ (12). Colocando os valores numéricos na equação (14), obtém-se que a massa de Lúcifer devia ser: 


$$
M_{L u}=2,7 \cdot 10^{23} \mathrm{~kg} \text {. }
$$

Como esperado a massa obtida é muito grande, porém menor que a massa da Terra. Observa-se, entretanto, que o valor da massa encontrada está situado entre a massa da Terra $\left(6,0.10^{24} \mathrm{~kg}\right)$ e a da Lua $\left(7,36.10^{22} \mathrm{~kg}\right)$, ou seja, esse valor seria compatível com um objeto celeste no contexto da época de Dante. Por outro lado, a colisão entre a Terra e um objeto com essa massa seria desastroso. Pode-se lembrar de que uma explicação bastante aceita para a extinção do período Cretáceo (responsável pelo desaparecimento dos grandes répteis) é a colisão de um asteroide com a Terra. Uma estimativa da massa desse asteroide aponta para cerca de $3,4.10^{13} \mathrm{~kg}$ (ALVAREZ,1980) que é cerca de dez ordens de grandeza menor que a massa calculada aqui.

\section{Considerações finais}

Neste trabalho foram usados princípios e modelos mecânicos da Física para provocar um olhar alternativo para o mito da queda de Lúcifer e da formação do Inferno e do Purgatório sob o ponto de vista da cosmologia vigente na Idade Média Europeia, explicitada na Divina Comédia de Dante (ALIGHIERE, 1595).

A obra de Dante tem despertado o interesse de diversos estudiosos e intelectuais desde sua publicação, ela também tem permitido discussões intensas sobre seu significado e conteúdo. Em termos técnicos, vale destacar a controversa entre Manetti (MANETTI, 1506) e Alessandro Vellutello (ALIGHIERI, 1544) que gerou um grande interesse por parte da comunidade acadêmica da época, a ponto de Galileu ser convidado a intervir.

No contexto do ensino de física, o presente trabalho apresenta contribuições em diversos aspectos que vão desde a motivação dos alunos para o aprendizado até a introdução e discussão dos conceitos físicos em si. Outras contribuições de caráter geral também podem ser observadas, como uma introdução à construção de modelos em Física e a comparação entre as visões de mundo contemporânea e medieval. Um estudo mais abrangente sobre a relação entre física e literatura com ênfase nas questões no potencial didático dessa relação pode ser encontrado no texto de Lima e Ricardo (2015).

Os cálculos realizados ao longo do texto podem ser repetidos por qualquer indivíduo com noções básicas de física e cálculo integral. Desta forma, estudantes dos cursos de ciências exatas devem ser capazes de acompanhar o procedimento adotado nesse trabalho logo após o primeiro ano de curso. Para os níveis mais básicos de ensino os detalhes matemáticos podem ser total ou parcialmente omitidos dependendo do perfil dos alunos e o objetivo pedagógico pretendido. No apêndice é apresentada uma sugestão de adequação do tema tratado aqui para o Ensino Médio.

Outras grandezas a respeito do problema podem também ser calculadas com raciocínio semelhante ao apresentado no decorrer desse texto. Neste sentido, são deixados ao leitor 
interessado dois exercícios: (1) o cálculo do tempo de queda de Lúcifer e (2) a estimativa da velocidade de recuo da Terra devido ao choque com o anjo caído.

É oportuno observar que os cálculos apresentados não dão suporte ao mito, apenas usam elementos da obra literária para inserir e discutir conceitos físicos, motivando e interrelacionando a física com outras áreas do conhecimento humano, em particular a literatura. A esse respeito é importante apontar que a estrutura do planeta, não responderia da forma indicada por Dante ao impacto de um corpo como o descrito aqui. Além do mais, hoje em dia, conhecendo a geografia de todo o planeta, especialmente a do hemisfério sul (austral), sabemos que a Montanha do Purgatório não existe.

\section{Agradecimentos}

EDF agradece a hospitalidade do Departamento de Física Teórica, Atómica y Óptica e o IMUVA (Instituto de Matemáticas) da Universidad de Valladolid, Valladolid, Spain, e reconhece que o ambiente acolhedor e estimulante dessa Instituição foi importante para a conclusão do presente artigo. Os autores também se encontram em débito com os árbitros que avaliaram criticamente o trabalho e fizeram comentários construtivos no sentido de melhorar o texto final.

\section{Referências}

ALIGHIERI, D. La Divina commedia di Dante Alighieri nobile fiorentino ridotta a miglior lezione dagli accademici della Crusca. Firenze: Domenico Manzani (tipógrafo), 1595.

ALIGHIERI, D. La comedia di Dante Aligieri con la noua espositione di Alessandro Vellutello. Venezia: Francesco Marcolini [tipógrafo] sob a instância de Alessandro Vellutello, 1544.

ALIGHIERI, D. La Divina commedia con nuovi argomenti e note di G. Borghi. Paris: Baudry, Libreria Europea, 1844.

ALVAREZ, L. W. et al. An Extraterrestrial Cause for the Cretaceous-Tertiary Extinction. Science, Washington, v. 208, n. 4448, p. 1095-1108, jun. 1980.

ANDRADE, R. R. D.; NASCIMENTO, R. S.; GERMANO, M. G. Influências da Física Moderna na Obra de Salvador Dalí. Caderno Brasileiro de Ensino de Física, Florianópolis, v. 24, n. 3, p. 400-423, dez. 2007.

BARATTA, M. Leonardo da Vinci e i problemi della terra. Torino: Fratelli Bocca, 1903.

FERREIRA, J. C. D; RABONI, P. C. A. A Ficção Científica de Júlio Verne e o Ensino de Física: Uma Análise de "Vinte Mil Léguas Submarinas". Caderno Brasileiro de Ensino de Física, Florianópolis, v. 30, n. 1, p. 84-103, abr. 2013. 
GALILEU, G. Lezioni di Galileo Galilei intorno la figura, sito e grandezza dell'Inferno di DanteAlighieri. In: GIGLI, Ottavio (Org.). Studi sulla Divina Commedia. Firenze: Le Monnier, 1855. p. 5-36.

GIGLI, O. (Org.). Studi sulla Divina Commedia. Firenze: Le Monnier, 1855.

GUILGER, F. J.; FORATO, T. C. M. A Divina Comédia de Alighieri e o Geocentrismo Medieval na Escola Básica. In: SIMPÓSIO NACIONAL DE ENSINO DE FÍSICA, XXI, 2015, Universidade Federal de Uberlândia. Caderno de resumos... p. 125. Disponível em: $<$ http://s3.amazonaws.com/academia.edu.documents/37850728/SNEF_Guilguer_2015.pdf? AWSAccessKeyId=AKIAJ56TQJRTWSMTNPEA\&Expires $=1472338799 \&$ Signature $=$ T9Xs Nhuv\%2BqqtC4gqrwHzTdYbLiA\%3D\&response-content-disposition=inline\%3B\%20filena me\%3DGUILGER_F.J._FORATO_T._C._M.._A_Divina.pdf>. Acesso em: 27 ago. 2016.

JÚDICE, R.; DUTRA, G. Física e Teatro. Física na Escola, São Paulo, v. 2, n. 1, p. 7-9, mai. 2001.

LIMA, L. G.; RICARDO, E. C. Física e Literatura: uma revisão bibliográfica. Caderno Brasileiro de Ensino de Física, Florianópolis, v. 32, n. 3, p. 577-617, dez. 2015.

LATINI, B. Tresor. Torino: Einaudi, 2007.

MANETTI, A. Dialogo di Antonio Manetti cittadino Fiorentino circa al sito, forma et misura dello Inferno di Dante Alighieri Poeta excellentissimo. In: GIGLI, O. (org.). Studi sulla Divina Commedia. Firenze: Le Monnier, 1855. p. 41-132.

MANETTI, A. Dialogo di Antonio Manetti cittadino Fiorentino circa al sito, forma et misura dello Inferno di Dante Alighieri Poeta excellentissimo. Florença: Giunta, 1506.

MECKE, K. R. A Imagem da Física na Literatura. Gazeta de Física, Portugal, v. 27, n. 1, p. 4-13, jan. 2004.

NEVES, M. C. D. A História da Ciência no Ensino de Física. Ciência \& Educação, Baurú, v. 5, n.1, p. 73-81, 1998.

PISKUNOV, N. Cálculo Diferencial e Integral. Moscou: Mir, 1983. p. 489-491.

RESNICK, R.; HALLIDAY, D. Física I. Rio de Janeiro: Livros Técnicos e Científicos Ed. S.A., 1974. p. 481.

SNOW, C. P. The Two culture. The New Statesman, 1956 (artigo original foi reeditado online em 2013 e está disponível no endereço da revista: $<$ http://www.newstatesman.com/cultural-capital/2013/01/c-p-snow-two-cultures >). Acesso em: 22 fev. 2016. 
ZANETIC, J. Física e cultura. Ciência e Cultura, Campinas, v. 57, n. 3, p. 21-24, jul./set. 2005.

ZANETIC, J. Física e literatura: construindo uma ponte entre as duas culturas. História, Ciências, Saúde - Manguinhos, Rio de Janeiro, v. 13, suppl., p. 55-70, out. 2006.

\section{APÊNDICE - Adaptações sugeridas para o Ensino Médio}

O presente trabalho foi pensado em sua forma e conteúdo para pode ser apresentado para estudantes do Ensino Superior. Entretanto, como indicado na conclusão do artigo, ele pode ser readequado para outros níveis de ensino. De forma ilustrativa, indicamos nesse apêndice como estimar a massa de Lúcifer usando conceitos e ferramentas matemáticas acessíveis aos alunos do Ensino Médio.

O cálculo da velocidade de queda do anjo usado no corpo do artigo envolve o princípio de conservação de energia. Especificamente, a variação da energia potencial de Lúcifer deve ser igual a sua energia cinética final (supondo que sua velocidade inicial é nula). Uma vez que a energia potencial gravitacional em sua forma geral é dada por $U=-\frac{G . M . m}{r}$, a variação da energia potencial é obtida pela expressão $\Delta U=-G M_{T} M_{L u}\left[\frac{1}{d_{T}}-\frac{1}{R_{T}}\right]$, como indicado no texto, equação (2).

Uma maneira mais simples, embora menos precisa, seria admitir a aceleração da gravidade constante $\left(\mathrm{g}=9,8 \mathrm{~m} / \mathrm{s}^{2}\right)$ e usar a equação de Torricelli:

$$
v^{2}=v_{0}^{2}+2 a \Delta \mathrm{s}=>v=\sqrt{2 a \Delta \mathrm{s}}=\sqrt{2 \cdot 9,8 \cdot 3,4 \cdot 10^{8}}=8,2 \cdot 10^{4} \mathrm{~m} / \mathrm{s}
$$

A notação segue a mesma usada no corpo do artigo, sendo $\Delta \mathrm{s}=\mathrm{d}_{\mathrm{T}}$ e $a=\mathrm{g}$. Essa expressão determina a velocidade do anjo caído ao atingir a superfície da Terra admitindo que sua velocidade inicial é zero e aceleração é constante. Como esperado a velocidade encontrada é maior que aquela indicada no texto $\left(v=1,1.10^{4} \mathrm{~m} / \mathrm{s}\right)$, esse resultado reflete o fato da aceleração ter um valor crescente ao longo da queda sendo seu valor máximo, próximo à superfície do planeta, igual a $\mathrm{g}=9,8 \mathrm{~m} / \mathrm{s}^{2}$.

Na determinação da massa, sem uso do cálculo integral, vamos fazer uma suposição adicional sobre a Montanha do Purgatório. Vamos admitir que o Centro de Massa (CM) da montanha coincide com seu Centro de Gravidade. Essa igualdade não é estritamente verdadeira para um corpo com a altura de $6,4 \cdot 10^{6} \mathrm{~m}$, equivalente ao raio da Terra. Entretanto, essa hipótese permite compatibilizar o raciocínio com o conhecimento adquirido no Ensino Médio.

Outra suposição adotada é que a energia potencial da montanha corresponde à energia potencial de um corpo próximo à superfície da Terra com a massa concentrada no seu CM. Em termos matemáticos: $\Delta \mathrm{U}=$ m.g.h, com h sendo a altura do Centro de Massa. Essa aproximação implica em admitir que a variação da energia potencial da montanha seria o equivalente a elevar uma massa m (massa da montanha) a uma altura h da superfície da Terra 
(posição do CM da montanha). No caso de um cone, o CM se encontra sobre o seu eixo, a um quarto de sua altura a partir da base. Esse resultado pode ser conseguido experimentalmente pelos estudantes usando um sólido no formato do cone e um fio pelo qual se suspende o cone de diferentes pontos sobre sua superfície.

A massa da montanha está determinada no corpo do artigo e corresponde ao produto da densidade da Terra pelo volume de um cone, o resultado obtido é $m=3,3.10^{23} \mathrm{~kg}$, equação (6). Assim, a energia potencial estimada da montanha é:

$$
\Delta U=m \cdot g \cdot h=3,310^{23} \cdot 9,8 \cdot \frac{6,410^{6}}{4} \cong 5,2 \cdot 10^{30} \mathrm{~J} .
$$

A massa de Lúcifer pode ser obtida seguindo os mesmos passos indicado no texto pelas equações de (13) a (16). Os conceitos usados nessa análise envolve conservação do momento linear e da energia. A diferença do resultado é apenas numérica, ou seja, substituição da energia potencial da montanha indicado pela equação (12) pelo valor obtido acima (A.2) e a velocidade de queda obtida pela equação (3) pelo valor aproximado obtido em (A.1). Nessas condições, a massa de Lúcifer seria dada por:

$$
M_{L u}=\frac{\Delta U+\sqrt{\Delta U\left(\Delta U+2 m v^{2}\right)}}{v^{2}}=>M_{L u} \approx 2,2.10^{22} \mathrm{~kg}
$$

Observa-se que a massa encontrada é cerca de uma ordem de grandeza menor que o valor indicado na equação (17). Essa discrepância é compreensível frente às aproximações mais fortes utilizadas nesse apêndice.

Um cálculo ainda mais simplificado pode ser feito considerando que toda a energia cinética do anjo caído se transforma em energia potencial da montanha. Nessa aproximação, a etapa da conservação do momento linear seria excluída e a energia cinética de Lúcifer e a energia potencial da Montanha do Purgatório seriam igualadas. Nesse caso, a diferença entre o resultado e o valor obtido no corpo do artigo seria ainda maior devido às aproximações serem mais pobres. 